\title{
Barrettides: A Peptide Family Specifically Produced by the Deep-Sea Sponge Geodia barretti
}

\author{
Karin Steffen, Quentin Laborde, Sunithi Gunasekera, Colton D. Payne, K. Johan Rosengren, Ana Riesgo, \\ Ulf Göransson, and Paco Cárdenas*
}

Cite This: J. Nat. Prod. 2021, 84, 3138-3146

Read Online

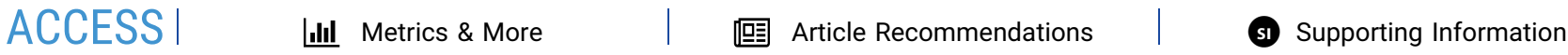

ABSTRACT: Natural product discovery by isolation and structure elucidation is a laborious task often requiring ample quantities of biological starting material and frequently resulting in the rediscovery of previously known compounds. However, peptides are a compound class amenable to an alternative genomic, transcriptomic, and in silico discovery route by similarity searches of known peptide sequences against sequencing data. Based on the sequences of barrettides $\mathrm{A}$ and $\mathrm{B}$, we identified five new barrettide sequences (barrettides $\mathrm{C}-\mathrm{G}$ ) predicted from the North Atlantic deep-sea demosponge Geodia barretti (Geodiidae). We synthesized, folded, and investigated one of the newly described barrettides, barrettide C (NVVPCFCVED-

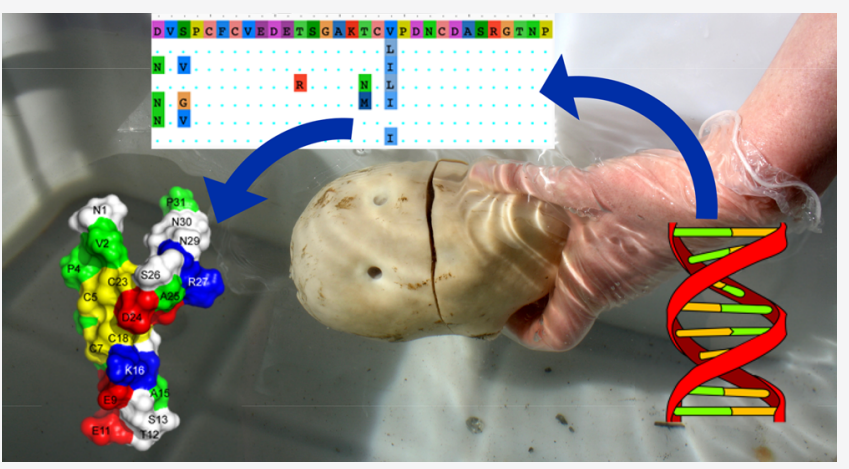
ETSGAKTCIPDNCDASRGTNP, disulfide connectivity I-IV,

II-III). Co-elution experiments of synthetic and sponge-derived barrettide $\mathrm{C}$ confirmed its native conformation. NMR spectroscopy and the anti-biofouling activity on larval settlement of the bay barnacle Amphibalanus improvisus (IC ${ }_{50} 0.64 \mu \mathrm{M}$ ) show that barrettide $\mathrm{C}$ is highly similar to barrettides $\mathrm{A}$ and $\mathrm{B}$ in both structure and function. Several lines of evidence suggest that barrettides are produced by the sponge itself and not one of its microbial symbionts.

$\mathrm{M}$ arine sponges are recognized as a prolific source of new marine natural products (NPs). ${ }^{1-3}$ However, these sponge NPs are frequently found to be produced by their associated microbes. ${ }^{4-12}$ Geodia barretti Bowerbank, ${ }^{13} 1858$ is a species of North Atlantic deep-sea demosponge well studied since the 1980 s for its natural products. ${ }^{14}$ To date, 12 small molecules have been reported to be associated with the sponge, namely, herbipolin, ${ }^{15-17}$ barettin, ${ }^{18}$ 8,9-dihydrobarettin, ${ }^{19}$ the diketopiperazine cyclo(Pro-Arg) and 8,9-dihydro8 -hydroxybarrettin, ${ }^{20}$ bromobenzisoxalone barettin, ${ }^{21}$ 6-bromoconicamin and 6-bromo-8-hydroxyconicamin, ${ }^{22}$ geobarrettins $\mathrm{A}, \mathrm{B}$, and $\mathrm{C}$, and L-6-bromohypaphorine, ${ }^{23}$ with a range of bioactivities. In addition, two bioactive peptides, barrettides $\mathrm{A}$ and $B$, have been isolated from G. barretti. ${ }^{24}$

The barrettide peptides are each composed of 31 amino acid residues, two disulfide bonds (Cys5-Cys23 and Cys7Cys18), and two antiparallel $\beta$-strands, which creates an overall $\beta$-hairpin structure. Barrettides $\mathrm{A}$ and $\mathrm{B}$ were found to inhibit biofouling by the bay barnacle Amphibalanus improvisus (Darwin, 1854). ${ }^{25}$ Carstens et al. ${ }^{24}$ further noted the presence of two additional peptidic masses at low abundance, $[\mathrm{M}+$ $2 \mathrm{H}]^{2+} 1619$ and 1648 . Isolation and structure elucidation of these low-abundance peptides would require a substantial amount of biomass, making this a nonviable strategy.

An alternative for discovering new peptides is straightforward BLAST searches using known peptide sequences as queries. These searches can be performed on transcriptomes that are abundant in sequencing databases. Such a data survey has the potential to address key challenges in natural product chemistry: (1) Sequencing data can be instrumental in identifying the true producer of (sponge) NPs. ${ }^{5,7-11}$ (2) By discovering new similar sequences, diversity of previously described peptides may be expanded and can be placed in the context of a larger family of compounds. (3) Appropriate sequencing data can be used to study the specificity or taxonomic distribution of an NP by establishing whether the compound is restricted to a single species or present in related taxa.

Here, our rationale was to investigate these three key challenges with respect to the barrettides, (i.e., their diversity, distribution, and origin) using high-throughput sequencing data of sponges in general and G. barretti in particular. As a proof of concept and to assess the validity of a predicted sequence, we synthesized and folded the predicted sequence

Received: October 1, 2021

Published: December 7, 2021 

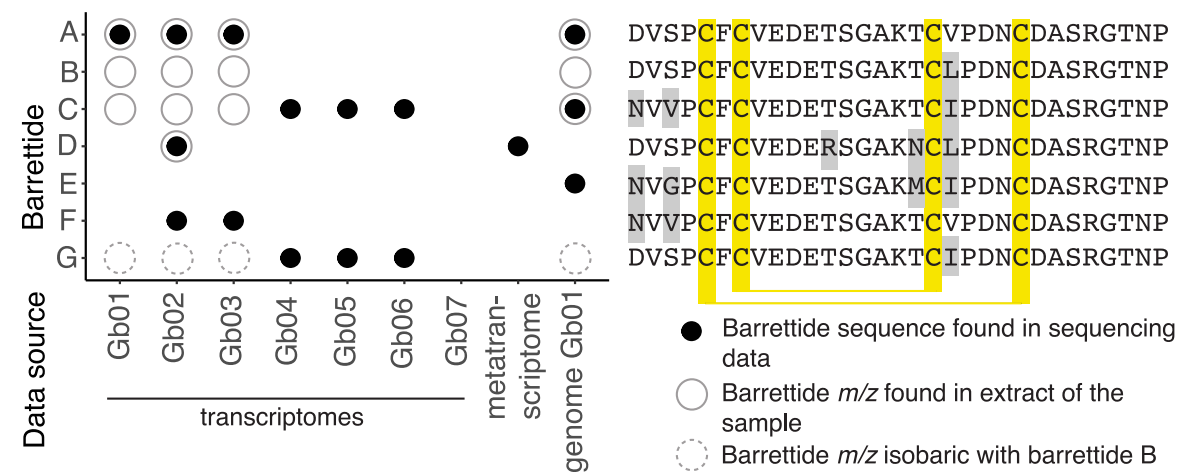

Figure 1. Identification of barrettides across different G. barretti samples. Full black circles: barrettide sequence found in respective sequencing data, open gray circles: barrettide $\mathrm{m} / z$ found in metabolic profile of the same sample. Dashed gray circles: $\mathrm{m} / z$ isobaric with barrettide B. The corresponding amino acid sequences are shown to the right, and amino acid differences to barrettide A are highlighted with gray shading. Gb07 did not yield any hits due to the quality filtering process removing most of the assembled transcripts.

Table 1. Barrettide $m / z$ with Cysteines Oxidized, Inferred from Their Respective Amino Acid Sequences and Mass Error from Experimental Data

$\begin{array}{cccccc}\text { barrettide } & {[\mathrm{M}+\mathrm{H}]^{+}} & {[\mathrm{M}+2 \mathrm{H}]^{2+}} & {[\mathrm{M}+3 \mathrm{H}]^{3+}} & {[\mathrm{M}+4 \mathrm{H}]^{4+}} & \text { experimental } \\ \text { A } & 3213.2864 & 1607.1468 & 1071.7670 & 804.0771 & 3212.307 \\ \text { B } & 3227.3020 & 1614.1547 & 1076.4389 & 807.5810 & 3226.3236 \\ \text { C } & 3238.3544 & 1619.6808 & 1080.1230 & 810.3441 & 3237.3762 \\ \text { D } & 3295.3507 & 1648.1790 & 1099.1218 & 824.5931 & 3294.3784 \\ \text { E } & 3226.3003 & 1613.6538 & 1076.1049 & 807.3305 & 4.6656 \\ \text { F } & 3224.3388 & 1612.6730 & 1075.4511 & 806.8401 & 807.5810\end{array}$

named barrettide $\mathrm{C}$, demonstrated its presence in the sponge, elucidated its structure using NMR spectroscopy, and tested its antifouling activity.

\section{RESULTS AND DISCUSSION}

In Silico Discovery. We gathered, processed, and refined a collection of sequencing data sets representative of the sponge phylum as a whole and for the species G. barretti in particular (Supporting Information Table S1). For G. barretti, transcriptomes were assembled from raw data for seven individuals. Quality filtering after assembly decreased the number of retained gene sets (and thus transcripts) quite drastically in some cases (Gb01: from 136297 to 102692 , Gb02: from 232941 to $196679, \mathrm{~Gb} 03$ : from 113124 to $96728, \mathrm{~Gb} 04$ : from 156088 to 110425 , Gb05: from 160210 to 94448 , Gb06: from 175753 to 113976 , Gb07: from 89358 to 8). While the number of genes is still excessive and should be taken with caution, it is to be expected for de novo transcriptome assemblies. For comparison, the number of genes predicted from sponge whole genomes range from 32309 in Sycon ciliatum ${ }^{26}$ to 40112 in Amphimedon queenslandica. $^{27,28}$ For the BLAST searches in G. barretti, in addition to the transcriptomes mentioned above, an assembled metatranscriptome ${ }^{29}$ and an in-house draft genome (unpublished) were included. The draft genome of G. barretti has a length of $144.8 \mathrm{Mb}$ across 4576 contigs and is estimated to be $93.9 \%$ complete with only $4.2 \%$ duplicated single orthologous genes (BUSCO v.3.0.2b). Beyond G. barretti, readily assembled transcriptomes from 63 additional sponge species were collected. Combined, these data sets include representatives of all four classes of sponges and add up to five Hexactinellida, four Calcarea, three Homoscleromorpha, and
52 Demospongiae (covering 15 out of the 22 current valid orders).

In total, searching G. barretti sequencing data yielded five new sequences, tentatively named barrettides $\mathrm{C}-\mathrm{G}$ (Supporting Information Tables S2, S3). The amino acid sequences of the predicted barrettides and their distribution across the sequencing data are shown in Figure 1; their $\mathrm{m} / z$ ions in Table 1 . These sequences have one to four amino acid changes compared to the prototypic barrettide A. After assembly of the raw data from the metatranscriptome, ${ }^{29}$ we found one fulllength barrettide sequence (D), contrary to previous findings which report a lack of barrettide sequences in the unassembled data. ${ }^{24}$ The previously published barrettide $B$ was not recovered from the sequencing data. For barrettides A, C, D, $\mathrm{F}$, and $\mathrm{G}$, transcripts contained the barrettide sequence in an open reading frame (ORF). The draft genome is derived from the same sample as the transcriptome Gb01 and contains two barrettides (C, E) not found in the transcriptomes. This could be due to these barrettides not being expressed at the time of collection or due to an assembly error. The fact that we do not recover barrettide B in DNA sequencing data of the G. barretti samples but another isobaric sequence (barrettide $G$ ) is not due to a mistake in the original publication. ${ }^{24}$ Supporting Information Tables S5 and S6 present the original amino acid analysis data as well as complementary information from peptide sequencing confirming the sequence of barrettide $B$ is valid and correct. However, the validation of barrettide G predicted from the transcriptome would require isolation and amino acid analysis, NMR, or other methods able to distinguish between isobaric amino acids.

In all other species' transcriptomes $(n=63)$, the BLAST searches and subsequent filtering revealed 15 sequences somewhat similar to barrettides A and B from 11 sponge transcriptomes of Demosponges and Hexactinellida (Support- 
ing Information Table S4). Given the conserved positions of cysteine residues, these hits could represent potential hairpin peptides in these sponge species. Although these searches included transcriptomes of four close relatives of G. barretti ( $G$. atlantica, G. macandrewi, G. phlegraei, G. hentscheli), full-length peptide sequence hits with high sequence similarity were only recovered from $G$. barretti sequencing data.

Barrettide sequences are directly coded in the DNA/RNA akin to the peptide NP class of ribosomally synthesized and post-translationally modified peptides (RiPPs), one of two classes of peptide NPs. ${ }^{30}$ However, barrettides do not contain any of the modifications characteristic for RiPPs. Yet, with the obtained sequences at hand, we searched for features analogous to the modular precursor peptides of RiPPs, which can contain a signal domain, leader and core peptide, and recognition sequences. ${ }^{30}$ The barrettide sequences and peptides presented here (Figure 1, Table 1) would correspond to the mature RiPPs derived from the core peptide. The only post-translational modifications present in barrettides are the formation of two disulfide bonds (Cys5-Cys23 and Cys7Cys18). As for RiPPs, the barrettide ORFs are consistently predicted to start with a signal peptide of 19 residues, MATKVALLVVSALIAVAAA/MAIKVALLAVSALIAVAAA. A region of variable length (either short (19) or long (105 or 112 residues)) is present between the predicted signal and the core peptide and could therefore constitute a segment analogous to the leader peptide (Supporting Information Table S3). At the end of the putative leader peptide, i.e., just before the start of the core barrettide, there is an Ala residue present in all sequences. In the framework of RiPPs, specific enzyme cleavage sites should be present in the sequence to cleave the different modules from the precursor peptide. In eukaryotes, signal peptidase I (SPase I, EC 3.4.21.89) typically cleaves off the signal peptide, ${ }^{31}$ while other sequence-specific peptidases cleave the leader peptide from the core peptide. For the barrettides, proteinase $\mathrm{K}$ (EC 3.4.21.62 and 3.4.21.64) and Asp-N endopeptidase (+ N-terminal Glu) (EC 3.4.24.33) were predicted to cleave between the Ala residue and the core peptide. Of these enzymes, only the EC numbers for SPase I yielded matches in the transcriptome annotation of Gb01. However, there are many other peptidases (EC 3.4.) annotated. Finally, after the last/C-terminal residue of the core peptide, a stop codon (TGA) is present in all sequences. In theory, the translation machinery would dissociate from the growing peptide when reaching the stop codon, and thus we have no C-terminal recognition sequences. Yet, at the RNA level, a conserved 3' UTR (untranslated region, approximately 33 nucleotides) is present. At this point, we cannot speculate about its function as BLAST searches of $3^{\prime}$ (and 5' UTRs) against the NCBI GenBank nucleotide collection did not result in any significant similarity. ${ }^{32}$

What Evidence Do We Have for the Origin of the Barrettides? Given the compositional complexity of sponges with their associated microbes (considered contamination in the sponge transcriptomes), evaluating evidence for either a prokaryotic (microbe) or eukaryotic (sponge) origin of the barrettides requires cautious assessment of the multiple levels of evidence. In less complex (i.e., uncontaminated) tissue samples, the presence of a transcript could be deemed sufficient evidence for the producer of a transcript and thus a compound. However, we detected contamination in sponge transcriptomes by a bimodal distribution of GC content as indicated by fastQC despite RNA sequencing library preparation steps to decrease the abundance of prokaryotic transcripts. Thus, the mere presence of a transcript is not sufficient evidence to implicate the sponge as its producer. We further investigated the transcripts for prokaryotic or eukaryotic characteristics. A sign of a mature eukaryotic transcript is a poly-A tail, i.e., "A"s (adenines) at the end of the nucleotide sequence. In two barettide transcripts from Gb04, we observed short poly-A tails. Investigating the specific transcript quality, by mapping back raw sequencing reads, did not strongly support the poly-A tails, as there was little continuous coverage of the transcript toward the tail of the sequences. In addition, poly-A tails are also found elsewhere, i.e., in bacteria and archaea (for degradation purposes). ${ }^{33}$ Therefore, this line of evidence seems inconclusive as to whether or not the sponge is the producer of the transcripts. Introns, noncoding regions in transcripts that are removed prior to translation, are typically regarded as a eukaryotic feature, although there are two types of introns ("group I" and "group II") found in prokaryotes. ${ }^{34-36}$ Aligning several isoforms (e.g., five isoforms hits for barrettide A in Gb03 or six isoforms for barrettide $G$ in Gb04) did reveal several introns. These introns ( $<100$ up to 400 nucleotides in length) did not yield any significant BLAST hits against the GenBank nucleotide collection. In our opinion, a true prokaryotic group I intron would have produced significant hits due to the conserved domains. Further, the introns found in our transcripts are too short to be prokaryotic group II introns (500-800 bp). Therefore, on the basis of intron length and lack of sequence similarity, we hypothesized the introns to be indicators of eukaryotic transcripts. Despite being at the draft stage, the genome, which has undergone in silico contamination removal, also contains genes for barrettides. We also checked metabolic profiles of $G$. barretti samples, acquired in the framework of an ecological study of sponge-derived chemistry (Steffen et al., unpublished), for barrettide C (Supporting Information Figure S1) and found a similar pattern to that for barrettides A and B, i.e., individual variation in expression not dependent on sample depth. The peptide thus seems constitutively produced, which could point toward the sponge as its producer. With this combined evidence at hand (eukaryotic introns, barrettide sequences present in the genome, constitutive expression), we think it is reasonable to suggest that sponges are the producers of the barrettides. This would make barrettides the first sponge-derived peptide NP attributed to the sponge and not a prokaryotic microbial symbiont.

Generally, sponges are known as a prolific source of natural products. $^{1-3,37}$ For natural products typically considered primary metabolites, such as sterols, ${ }^{38}$ sponges have been established as the producers. ${ }^{2,39-41}$ However, many spongederived natural products typically considered as "secondary" or "specialized" metabolites have been found to be of microbial origin. ${ }^{4-12}$ For various "secondary" NPs, localization studies show association with sponge cells. ${ }^{42,43}$ Further, in some cases, sphaerulous cells loaded with natural products were found to be exuded by sponges (e.g., in Crambe crambe and Aplysina fistularis)..$^{44,45}$ However, Haliclona sp. was found to harbor intracellular symbionts producing specialized metabolites, which would refute the underlying assumption that sponge cell localization is sufficient evidence to implicate the sponge as the producer of the metabolite. ${ }^{7,46}$ This finding highlights the importance of determining the genetic proof of NP production. Also, compounds could be taken up by sponge 

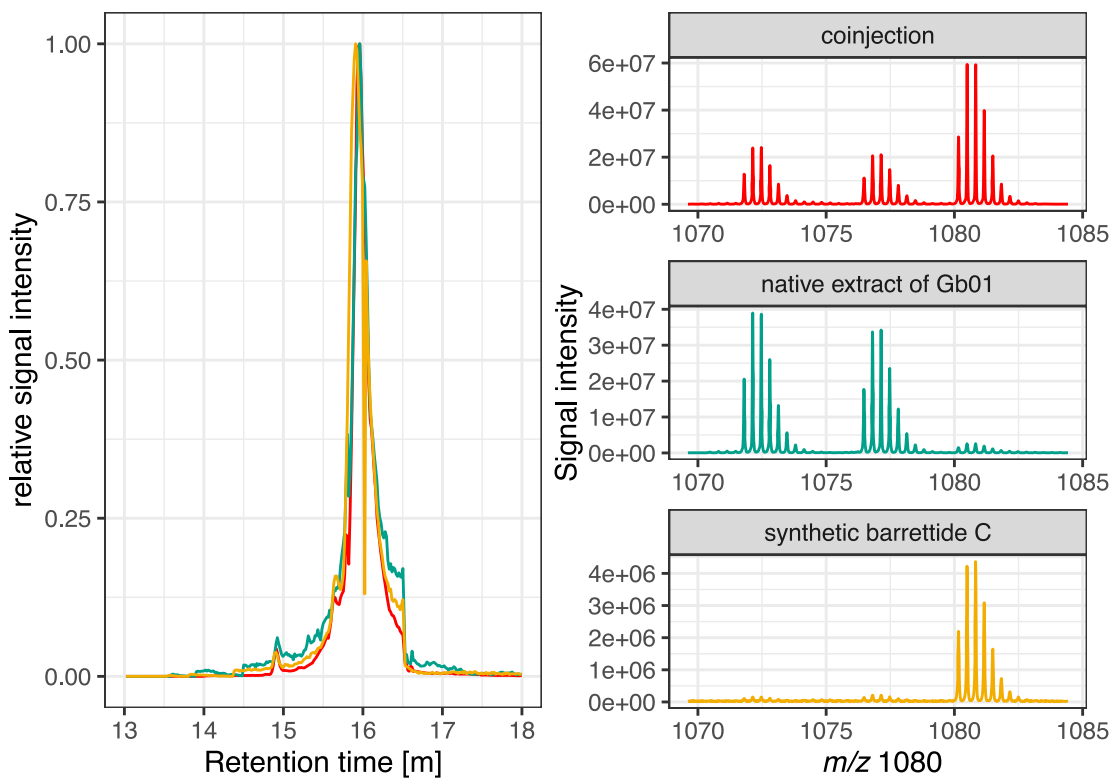

Figure 2. Left: Selected ion mass chromatograms for the $m / z 1080[\mathrm{M}+3 \mathrm{H}]^{3+}$ of barrettide $\mathrm{C}$. The synthetic peptide (yellow) has the same retention time $\left(t_{\mathrm{R}}\right)$ as the $\mathrm{m} / z$ observed in the native chemical profile (turquoise). Likewise, the native chemical extract spiked with synthetic barrettide $\mathrm{C}$ (red) only shows one peak at the same $t_{\mathrm{R}}$. Right: Isotopic patterns show a signal increase in the spiked native extract both in absolute terms and relative to the intensities of barrettide $\mathrm{A}\left([\mathrm{M}+3 \mathrm{H}]^{3+} 1071\right)$ and $\mathrm{B}\left([\mathrm{M}+3 \mathrm{H}]^{3+} 1076\right)$.

cells after being produced by a microbe. Alternative to DNA sequencing, fluorescence in situ hybridization methods have been used to establish the bacterial origin of a sponge-derived peptide. $^{47}$

Detecting Barrettide Presence by LC-MS. Based on the amino acid sequences and disulfide connectivity, the calculated $[\mathrm{M}+2 \mathrm{H}]^{2+}$ of barrettides $\mathrm{C}$ and $\mathrm{D}$ (1619.6808 and 1648.1790, respectively) matched the masses observed in a previous extract. ${ }^{24}$ To follow up on barrettide reports from the transcriptomes, we searched metabolic profiles of samples Gb01, Gb02, and Gb03, observing $m / z$ from barrettide A to C, $A$ to $D$, and $A$ to $C$, respectively (Figure 1 ). We do not have extracts for samples Gb04, Gb05, Gb06, and Gb07 and cannot corroborate the presence of barrettides by their $\mathrm{m} / z$. The detection of predicted barrettide $G$ would require additional methods for verification, as it is isobaric with barrettide $B$; the sequences only differ by an interchange of leucine/isoleucine. Beyond G. barretti, we did not observe barrettides $\mathrm{m} / z$ in extracts of $G$. atlantica (UPSZMC 78293), G. macandrewii (UPSZMC 78255), G. phlegraei (UPSZMC 167249), or G. hentscheli (UPSZMC 78266) corroborating the limitation of barrettides to G. barretti observed in the transcriptomic data.

The comparison of transcriptome surveys and MS data showed that the two kinds of data capture different aspects of the biology and physiological output of the organisms. Sequences retrieved from transcriptomes were confirmed by their corresponding $\mathrm{m} / z$ (barrettide $\mathrm{A}$ in Gb01, Gb02, and Gb03 and barrettide D in Gb02). However, some barrettides predicted from the transcriptome were not found in the MS data (barrettide $\mathrm{F}$ in $\mathrm{Gb02}$ and $\mathrm{Gb03}$ ) and vice versa (barrettides B and C in Gb01, Gb02, and Gb03). A number of plausible mechanisms could explain these discrepancies starting from technical reasons, e.g., sequencing errors or misassemblies in the transcriptome, sensitivity of MS analyses to biological explanations such as modifications of transcripts (degradation), post-translational modifications of the barrettide precursor peptide, or storage/accumulation of previously produced barrettides in the sponges, or simply lack of expression. Barrettide $\mathrm{E}$ was only present in the genome and appeared not to be expressed at either the transcriptome or the metabolome level.

Peptide Synthesis and LC-MS. Barrettide C was chosen for experimental validation of the sequence predictions, as it was present in all investigated metabolic profiles. The peptide was synthesized on a solid support using standard Fmoc $[\mathrm{N}-(9-$ fluorenyl)methoxycarbonyl] chemistry. As the C-terminal Pro is prone to diketopiperazine formation that leads to cleavage of the emerging peptide chain from the resin, we chose 2chlorotrityl chloride (2-CTC) as the resin to avoid this reaction. Pro was coupled as the first residue, and the peptide was assembled by manual synthesis. As in previous work, we incorporated a dipeptide, in our case Fmoc-Ser(tBu)-(Dmb)Gly-OH, at positions 18 and 19 to prevent peptide aggregation and improve synthesis yield. ${ }^{24}$ Using this approach, the peptide could be synthesized in good yields and was subsequently successfully folded and purified. The peptide had good solubility in water in both reduced and oxidized form. A coelution experiment was performed by LC-MS comparing synthetic barrettide $\mathrm{C}$ with a sponge extract containing native barrettide $\mathrm{C}$ (Gb01) and the native extract spiked with the synthetic barrettide $C$ (Figure 2). Retention times and isotopic patterns confirmed that the synthetic barrettide $\mathrm{C}$ and the native compound were the same.

Structure Determination of Barrettide C and Comparison to Barrettide A. Previously discovered sequences of barrettides are highly similar with most observed amino acid changes being conservative (Figure 1). Thus, one would expect their 3D structures to be highly conserved. To confirm the fold of barrettide C, a sample containing $2.2 \mathrm{mg} / \mathrm{mL}$ peptide was prepared for NMR spectroscopy and data were recorded at 600 MHz. Intriguingly, while the signal dispersion was excellent, the line width was broader than expected and far more signals than expected were present in the 2D TOCSY and NOESY data. A closer inspection and partial resonance assignments 
revealed that up to three similar, but subtly different spin systems were present for each amino acid. These spin systems represent conformational states that are in chemical exchange with each other, evident from intense cross-peaks between all involved resonances in both the NOESY and TOCSY data (Supporting Information Figure S2). While this resulted in a highly complex spectral appearance and prevented further indepth analysis, we concluded the phenomena must be due to a dynamic multimerization process in which peptides are rapidly associating and disassociating. The NMR sample was consequently diluted 4-fold, and all data were rerecorded. Under these conditions, the lines were generally sharp, and all extra peaks had disappeared, allowing near complete resonance assignments using sequential assignment strategies. ${ }^{48}$ A full 3D structure was calculated based on interproton distance restraints, dihedral angles, and hydrogen bond restraints. The structure of barrettide $\mathrm{C}$ revealed a $\beta$-hairpin fold that is highly similar to the previously discovered and characterized barrettide A. ${ }^{24}$ Barrettide $\mathrm{C}$ contains two antiparallel $\beta$-strands, separated by a short loop, that are bridged by ladder-like disulfide bonds in a I-IV/II-III pattern (Cys5-Cys23 and Cys7-Cys18); in addition, a short $\alpha$-helix is formed on the Cterminal side of the $\beta$-hairpin which is stapled to the $\mathrm{N}$ terminal tail by the I-IV disulfide bond (Figure 3A). The structural statistics of barrettide $\mathrm{C}$ are presented in Table 2 and highlight the high quality of the structure and the agreement with the observed experimental data. The generated structures were of the 96th percentile of MolProbity scores, with $97 \%$ of residues falling within favored Ramachandran space and no outliers or poor rotamers present. Comparing the $\beta$-hairpin portion of barrettides $A$ and $C$ revealed a high structural similarity with a shared RMSD of $0.72 \AA$ (Figure $3 \mathrm{~B}$ ). Despite barrettides $\mathrm{A}$ and $\mathrm{C}$ only differing by one residue within the ordered regions, barrettide $\mathrm{C}$ contains a short $\alpha$-helix that was not observed in barrettide $\mathrm{A}$. The data generated by barrettide $\mathrm{C}$ agree with the formation of this $\alpha$-helical region with both temperature coefficients and preliminary calculations supporting the formation of the $i-i_{+4}$ hydrogen bonds expected of an $\alpha$-helix as well as TALOS-N predicting $\alpha$-helical backbone angles. The structure has a significant hydrophobic patch, as shown in Figure 3C, and it is possible that it is responsible for the observed aggregation at higher concentration. Alternatively, two or more peptides may self-associate via their $\beta$ sheets to create intermolecular $\beta$-strand interactions and hydrogen bonds. The structure was deposited at PDB under 7SAG.

Antifouling Assay and Biological Role. Prompted by the clean surface of the sponge, previous work on G. barretti compounds tested for biofouling inhibition. ${ }^{19,49}$ To follow up and further support the hypothesis that barrettide $\mathrm{C}$ belongs to a family of anti-biofouling peptides, we replicated the previous experimental setup. ${ }^{19,49}$ Settlement of bay barnacles was significantly inhibited at concentrations of $0.6 \mu \mathrm{M}\left(\chi^{2}\right.$ test $p$ $\left.=6.255 \times 10^{-5}\right)$ and $6 \mu \mathrm{M}\left(\chi^{2}\right.$ test, $\left.p=7.206 \times 10^{-11}\right)$ barrettide $\mathrm{C}$ with an $\mathrm{IC}_{50}$ of $0.64 \mu \mathrm{M}$ (Figure 4). These results were very similar to the activities of barrettides $A$ and $\mathrm{B}^{24}$ and are in the range of commercially available but toxic antifouling compounds ( $\mathrm{EC}_{50}$ TBTO (bis(tributyltin)oxide) $0.09 \mu \mathrm{g} / \mathrm{mL}$ or $0.15 \mu \mathrm{M}$ and Sea-Nine $0.3 \mu \mathrm{g} / \mathrm{mL}$ or $1.23 \mu \mathrm{M}) .{ }^{50}$ In contrast to previous work, we did not observe mortality during the experiment. At the highest treatment concentration, larval motor skills seemed impaired. While still occasionally moving
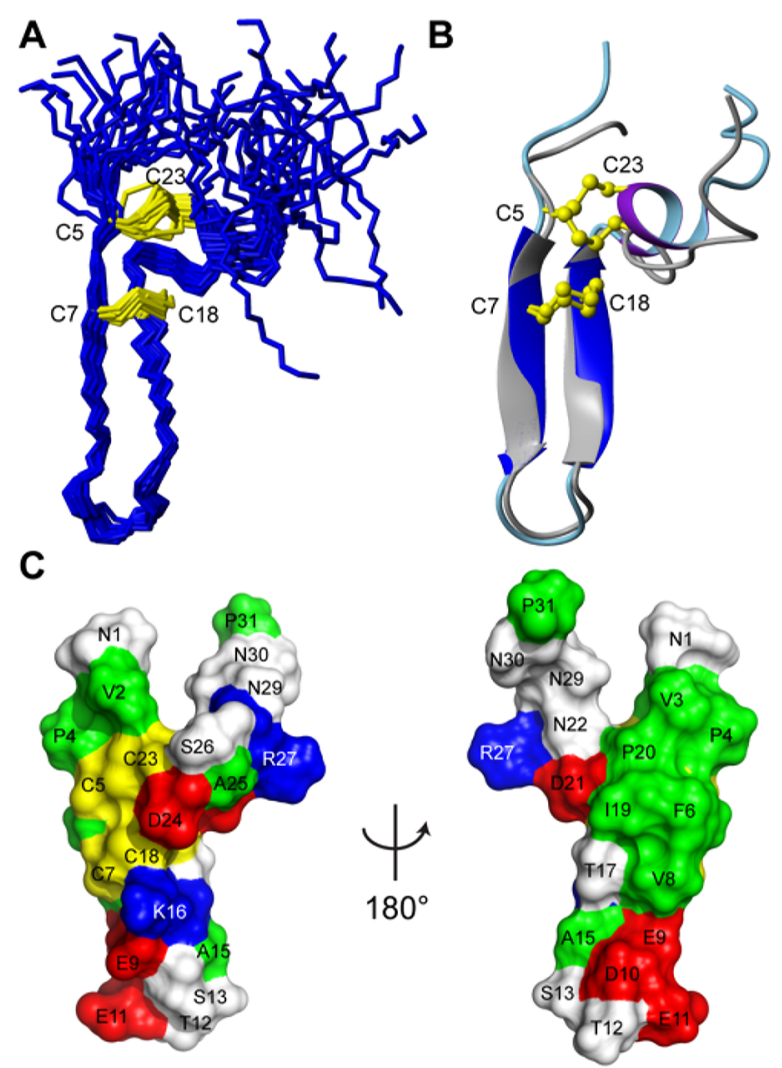

Figure 3. Solution NMR structure of barrettide $C$ and comparison to barrettide A. (A) Superimposed structural ensemble of barrettide $C$ in stick format, with disulfide bonds in yellow. (B) Superimposition of barrettide $\mathrm{C}$ (dark blue $\beta$-sheet, light blue backbone, and purple $\alpha$ helix) and barrettide $\mathrm{A}$ (gray $\beta$-sheet and backbone) in ribbon format with ball-and-stick disulfide bonds in yellow. This superimposition highlights the conserved $\beta$-hairpin structure of the barrettides. (C) Surface representation of barrettide C. Colors are used to denote residue side chain properties: negatively charged (red), positively charged (blue), hydrophobic (green), disulfide (yellow), and polar (white). Individual amino acids are also labeled for orientation.

their limbs, larvae did not move forward (or in any direction) in the Petri dishes.

Appropriate sequencing data allow one to investigate whether a certain compound is produced in response to an elicitor such as a competitor, ecological change, or another biological process. The number of transcriptomes is too small to draw any definite conclusions, but they allow for interesting speculation on the biology of the organisms and potential function of the peptides. For instance, the barrettide expression patterns for Gb01, Gb02, Gb03 and Gb04, Gb05, Gb06 are "mutually exclusive". The first group of specimens were all collected in one locality, at one time, and they were not reproducing at the time of collection, whereas the latter group were all collected in different localities and season from the first group and two of them were reproducing (Gb04: female, Gb05: nonreproductive, Gb06: female). ${ }^{51}$ Thus, the barrettide pattern invites hypotheses about their expression as a function of biology (reproduction or general physiology, population differentiation) or the environment (nutrients, biotic/abiotic elicitors). From a phylogenetic perspective, the finding that $G$. hentscheli, the sister species of G. barretti, ${ }^{52}$ does not produce barrettides suggests these peptides may have appeared fairly recently in evolutionary terms. G. barretti and G. hentscheli 
Table 2. NMR Distance and Dihedral Statistics for Barrettide C

\begin{tabular}{|c|c|}
\hline \multicolumn{2}{|l|}{ Distance restraints } \\
\hline sequential $(|i-j| \leq 1)$ & 159 \\
\hline medium range $(1<|i-j|<5)$ & 26 \\
\hline long range $(|i-j| \geq 5)$ & 56 \\
\hline hydrogen bonds & 16 (8 H-bonds) \\
\hline total & 257 \\
\hline \multicolumn{2}{|l|}{ Dihedral angle restraints } \\
\hline$\phi$ & 23 \\
\hline$\psi$ & 25 \\
\hline total & 48 \\
\hline \multicolumn{2}{|l|}{ Energies $(\mathrm{kcal} / \mathrm{mol}$, mean $\pm \mathrm{SD})$} \\
\hline overall & $-992.94 \pm 50.14$ \\
\hline bonds & $11.34 \pm 0.80$ \\
\hline angles & $26.14 \pm 2.44$ \\
\hline improper & $11.88 \pm 1.48$ \\
\hline dihedral & $129.70 \pm 1.37$ \\
\hline van der Waals & $-81.02 \pm 5.90$ \\
\hline electrostatic & $-1091.30 \pm 47.09$ \\
\hline NOE & $0.01 \pm 0.01$ \\
\hline constrained dihedrals & $0.31 \pm 0.20$ \\
\hline \multicolumn{2}{|l|}{ Atomic RMSD $(\AA)$} \\
\hline mean global backbone $(5-23)$ & $0.76 \pm 0.27$ \\
\hline mean global heavy atoms $(5-23)$ & $1.35 \pm 0.26$ \\
\hline \multicolumn{2}{|l|}{ Molprobity } \\
\hline clashes (>0.4 $\AA / 1000$ atoms) & $4.60 \pm 2.36$ \\
\hline poor rotamers & $0 \pm 0$ \\
\hline favored rotamers (\%) & $97.22 \pm 3.15$ \\
\hline Ramachandran outliers (\%) & $0 \pm 0$ \\
\hline Ramachandran favored (\%) & $97.41 \pm 2.20$ \\
\hline MolProbity score & $1.36 \pm 0.19$ \\
\hline MolProbity score percentile & $96.47 \pm 3.10$ \\
\hline \multicolumn{2}{|c|}{ Violations from experimental restraints } \\
\hline NOE violations exceeding $0.2 \AA$ & 0 \\
\hline dihedral violations exceeding $2.0^{\circ}$ & 0 \\
\hline
\end{tabular}

diverged possibly during the glacial/interglacial cycles of the Quaternary period (approximately 2.6-0.0 Mya). ${ }^{53}$

In conclusion, we increase barrettide diversity by reporting five new barrettide sequences $(C-G)$ discovered from highthroughput sequencing data of $G$. barretti. Four barrettides (C,
D, F, G) are found in open reading frames. Barrettides $\mathrm{C}$ and $\mathrm{D}$ are further supported by mass spectrometric evidence from extracts of the sponge species. Regarding their distribution, the barrettides were found to be restricted to G. barretti, but there is evidence for similar hairpin peptides in other sponge species. We acknowledge that these questions are not exclusively addressed by sequencing data and can also be answered with equivalent MS-based experiments, ${ }^{4}$ but sequencing data are easily accessed and shared. The predicted barrettide $\mathrm{C}$ was synthesized and folded, and its native conformation was confirmed via coelution. Both NMR spectroscopy and antifouling assays yielded similar results to the previously described barrettides A and B. On the basis of the similarities in terms of sequence, structure, and activity among all predicted and investigated barrettides, we hypothesize that barrettides are a family of antifouling peptides. Evidence from sequencing data leads us to suggest the sponge as the producer of the barrettides. This work showcases how analytical chemistry and molecular biology go hand in hand, allowing for the expansion of peptide families. It also highlights the importance of including several samples and orthogonal methods for natural product discovery, as none of the data sets (genome, transcriptomes, metabolic profiles) on their own encompassed the barrettide's diversity.

\section{EXPERIMENTAL SECTION}

NMR Spectroscopy. Lyophilized peptide $(1 \mathrm{mg})$ was dissolved in $220 \mu \mathrm{L}$ of $\mathrm{H}_{2} \mathrm{O} / \mathrm{D}_{2} \mathrm{O}(9: 1, \mathrm{v} / \mathrm{v})$ at $\mathrm{pH} 5.15(1.4 \mathrm{mmol} / \mathrm{L})$. As this initial sample proved to be too concentrated, it was diluted $1: 3 \mathrm{H}_{2} \mathrm{O}$ / $\mathrm{D}_{2} \mathrm{O}(9: 1, \mathrm{v} / \mathrm{v})(0.35 \mathrm{mmol} / \mathrm{L})$. This diluted sample was used to acquire one- and two-dimensional spectra $\left({ }^{1} \mathrm{H}-{ }^{1} \mathrm{H}\right.$ TOCSY, ${ }^{1} \mathrm{H}-{ }^{1} \mathrm{H}$ NOESY, $\left.{ }^{1} \mathrm{H}-{ }^{15} \mathrm{~N} \mathrm{HSQC}\right)$ at $298 \mathrm{~K}$. An additional set of TOCSY spectra acquired at temperatures of $288,293,298,303$, and $308 \mathrm{~K}$ was used to obtain amide temperature coefficients. In addition, a series of ${ }^{1} \mathrm{H} 1 \mathrm{D} / \mathrm{TOCSY}$ spectra to monitor hydrogen-deuterium exchange as well as a ${ }^{1} \mathrm{H}-{ }^{13} \mathrm{C}$ HSQC spectrum were acquired at $298 \mathrm{~K}$ on a lyophilized peptide sample dissolved in $100 \% \mathrm{D}_{2} \mathrm{O}$. All data, including TOCSY (mixing time $80 \mathrm{~ms}$ ), NOESY (mixing time $200 \mathrm{~ms}$ ), and HSQC spectra, were recorded and processed using Topspin 4.1.1 (Bruker). Generally, 4096 data points were collected in the F2 dimension and 256 ( 128 complex) points in F1, with 512 increments of 8 scans over $11194 \mathrm{~Hz}$. NMR spectra were acquired on a Bruker Avance Neo $600 \mathrm{MHz}$ (TCI (CRPHe TR- ${ }^{1} \mathrm{H}$ and ${ }^{19} \mathrm{~F} /{ }^{13} \mathrm{C} /{ }^{15} \mathrm{~N} 5$ mm-EZ)) spectrometer.
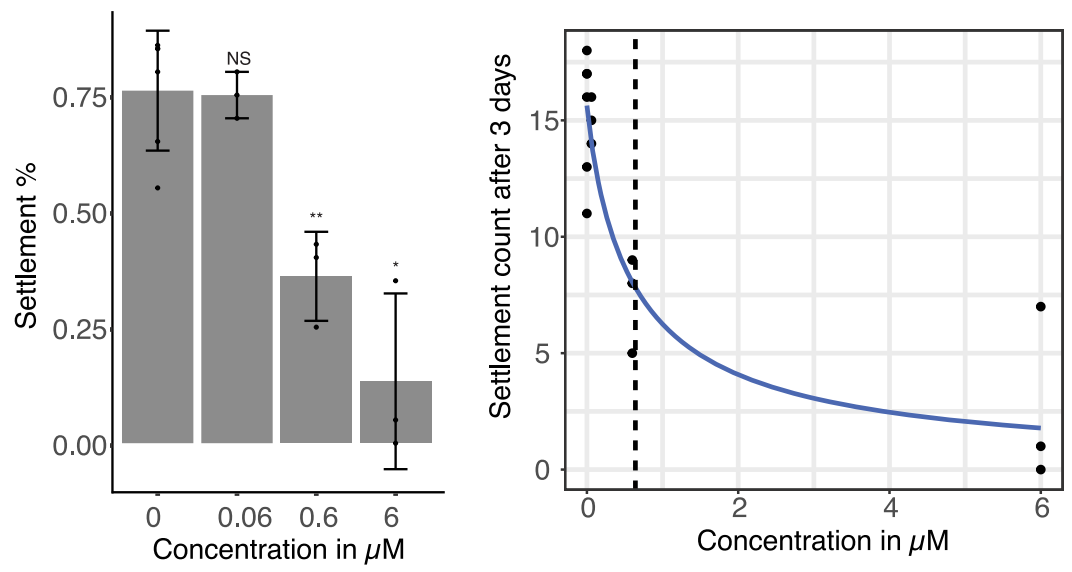

Figure 4. (Left) Larval settlement after 3 days of incubation with barrettide C. No mortality was observed. The experiments were performed in triplicate with $n=20( \pm 2)$ larvae per assay. Statistical evaluation was performed using a $\chi^{2}$ test comparing treatments to control. (Right) Doseresponse curve of barnacle larval settlement after 3 days of incubation with barrettide $\mathrm{C}$. $\mathrm{Th}^{\mathrm{IC}} \mathrm{IC}_{50}$ is indicated as a dashed line. 
Structure Calculation of Barrettide C. The structure of barrettide $\mathrm{C}$ was calculated using interproton distance restraints derived from the peak volumes of NOESY cross-peaks and dihedral $\phi$ $\left(\mathrm{C}_{-1}-\mathrm{N}-\mathrm{CA}-\mathrm{C}\right)$ and $\psi\left(\mathrm{N}-\mathrm{CA}-\mathrm{C}-\mathrm{N}_{+1}\right)$ backbone angles generated by torsion angle likelihood obtained from shift and sequence similarity (TALOS-N). ${ }^{54}$ Potential hydrogen bond donors were identified via the determination of backbone amide temperature coefficients. The chemical shift of the ${ }^{1} \mathrm{HN}$ proton of each residue was plotted against temperature, with values $>-4.6 \mathrm{ppb} / \mathrm{K}$ for the coefficient of the linear relationship taken as indicative of potential hydrogen bond donation. ${ }^{55}$ Hydrogen bond acceptors were determined during initial structure calculation. An initial set of structures (50) was generated through torsion angle dynamics and automated NOESY assignment using CYANA. ${ }^{56}$ The final 50 structures were annealed and refined in explicit water within CNS $1.21^{57}$ using protocols from the RECOORDscript database. All structures, containing no violations, were subjected to stereochemical analysis using MolProbity ${ }^{58}$ via comparison to structures published in the Protein Data Bank (PDB). From the final 50 structures, a set of 20 structures containing no violations, low energy, and best MolProbity scores was chosen. Final structures, restraints, and the chemical shift data for barrettide $\mathrm{C}$ have been submitted to the PDB (7SAG) and BRMB (30952).

Previous Metabolic Profiles. Extracts from museum specimens identified by PC (deep sea NW Atlantic G. atlantica (UPSZMC 78293), G. macandrewii (UPSZMC 78255), G. phlegraei (UPSZMC 167249), G. hentscheli (UPSZMC 78266)) as well as samples Gb01, $\mathrm{Gb} 02$, and Gb03 were prepared following Cárdenas. ${ }^{59}$ In short, tissue subsamples were lyophilized and manually ground to a fine powder. A sample of $50 \mathrm{mg}$ of powder was extracted using $4 \mathrm{~mL}$ of $60 \% \mathrm{MeCN}$ and $0.1 \%$ formic acid (FA) in $\mathrm{H}_{2} \mathrm{O}$ on a shaking table for $2 \mathrm{~h}$, the sample was precipitated at $3000 \mathrm{rpm}$ for $10 \mathrm{~min}$, the supernatant was collected, and the extraction was repeated with $30 \% \mathrm{MeCN}$ and $0.1 \%$ FA in $\mathrm{H}_{2} \mathrm{O}$ and then with $0.1 \% \mathrm{FA}$ in $\mathrm{H}_{2} \mathrm{O}$. The combined extracts $\left(12 \mathrm{~mL}\right.$ ) were diluted with $24 \mathrm{~mL}$ of $0.1 \% \mathrm{FA}$ in $\mathrm{H}_{2} \mathrm{O}$ and desalted on a solid phase extraction (SPE) $\mathrm{C}_{18}$-EC column (Isolute, $10 \mathrm{~mL}, 500$ $\mathrm{mg}$ ). The columns had been solvated in methanol overnight, rinsed with $20 \mathrm{~mL}$ of $60 \% \mathrm{MeCN} / 0.1 \% \mathrm{FA}$ in $\mathrm{H}_{2} \mathrm{O}$, and equilibrated with 20 $\mathrm{mL}$ of $10 \% \mathrm{MeCN} / 0.1 \% \mathrm{FA}$ in $\mathrm{H}_{2} \mathrm{O}$ prior to loading the diluted extracts. The columns were washed with $10 \mathrm{~mL}$ of $10 \% \mathrm{MeCN} / 0.1 \%$ FA in $\mathrm{H}_{2} \mathrm{O}$, and less polar compounds were eluted with $5 \mathrm{~mL}$ of $60 \%$ $\mathrm{MeCN} / 0.1 \%$ FA in $\mathrm{H}_{2} \mathrm{O}$ and lyophilized.

UPLC-MS. For coelution experiments and acquisition of sponge metabolic profiles, lyophilized extract (and/or synthetic barrettide C) was dissolved in $10 \% \mathrm{MeCN} / 0.1 \% \mathrm{FA}$ in $\mathrm{H}_{2} \mathrm{O}(4 \mu \mathrm{L} / \mathrm{mg}$ of sponge dry mass). Samples were analyzed with a Waters nanoAcquity ultra performance liquid chromatography (UPLC) system coupled to a Micromass Q-Tof micro mass spectrometer (MS), operated in positive mode and equipped with a nanolockspray interface. A BEH130 C18 nanoAcquity UPLC column $(75 \mu \mathrm{m} \times 250 \mathrm{~mm}, 1.7$ $\mu \mathrm{m})$ was used for separation. A linear gradient elution from $1 \%$ to $90 \% \mathrm{~B}$ over $50 \mathrm{~min}$ followed by isocratic cleaning for $4 \mathrm{~min}$ and reequilibration with $99 \%$ A was used, with mobile phase A (0.1\% FA/ $0.05 \% \mathrm{MeCN}$ in $\left.\mathrm{H}_{2} \mathrm{O}\right)$ and $\mathrm{B}(0.1 \% \mathrm{FA}$ in $\mathrm{MeCN})$. The injection volume was $0.10 \mu \mathrm{L}$ and the flow rate was $0.25 \mu \mathrm{L} / \mathrm{min}$ with a pressure between 7000 and 10000 psi. Total analysis time was 75 $\mathrm{min}$, and the $\mathrm{m} / z$ scan range was 50-1500. The spectra were analyzed with the program MassLynx (v. 4.1 Waters).

Solid Phase Peptide Synthesis (SPPS). Barrettide C was manually synthesized on 2-CTC resin $(1.6 \mathrm{mmol} / \mathrm{g})$ chlorinated overnight with $120 \mu \mathrm{L}$ of thionyl chloride, $200 \mu \mathrm{L}$ of pyridine, and approximately $4 \mathrm{~mL}$ of $\mathrm{CH}_{2} \mathrm{Cl}_{2}$. The first amino acid $(0.632 \mathrm{mmol})$ dissolved in $\mathrm{CH}_{2} \mathrm{Cl}_{2}$ was coupled with 7 equiv of $\mathrm{N}, \mathrm{N}$ diisopropylethylamine (DIPEA) overnight. The resin was washed and dried, and the new loading was estimated by weight increase $(0.85 \mathrm{mmol} / \mathrm{g}$ resin). The synthesis procedure included deprotection with $20 \%$ piperidine twice, for 1 and $20 \mathrm{~min}$, respectively, and amino acid coupling using 5 equiv of AA, 10 equiv of $1 \mathrm{M} \mathrm{DIC}$, and 10 equiv of $2 \mathrm{M}$ OxymaPure $(30 \mathrm{~min} \times 2)$. Ser and Gly in position 18 and 19 , respectively, were replaced by coupling the Fmoc-Ser $(\mathrm{tBu})-(\mathrm{Dmb})$ -
Gly-OH dipeptide to improve synthesis efficiency. The deprotected peptide was cleaved off the resin by incubating in a cleavage mixture with trifluoroacetic acid (TFA), triisopropylsilane (TIPS), and $\mathrm{H}_{2} \mathrm{O}$ $(9.5: 0.25: 0.25, \mathrm{v} / \mathrm{v})$ for $2 \mathrm{~h}$. The crude peptide was dissolved in $20 \%$ $\mathrm{MeCN}$ in $\mathrm{MQ}-\mathrm{H}_{2} \mathrm{O}$ and purified on an RP-HPLC system (Shimadzu LC-20) with a preparative column (Jupiter $15 \mu \mathrm{m}, \mathrm{C} 18,300 \AA, 250 \times$ $21.2 \mathrm{~mm}$, Phenomenex) on a linear gradient of $5-90 \%$ solvent $B$ ( $\mathrm{MeCN}$ with $0.05 \% \mathrm{TFA}$ ). The presence of the peptide in the fractions was assessed by MS (ThermoQuest Finnegal LCDeca). Fractions containing the peptide were lyophilized then oxidatively folded with a buffer of $1 \mathrm{M} \mathrm{NH}_{4} \mathrm{HCO}_{3}, 4 \mathrm{mmol}$ of glutathione disulfide (GSSG), $20 \mathrm{mmol}$ of glutathione (GSH), and peptide dissolved in $5 \mathrm{~mL}$ of $\mathrm{MQ}-\mathrm{H}_{2} \mathrm{O}$ with stirring overnight. The peptide was fractionated on a semipreparative column (Jupiter $5 \mu \mathrm{m}, \mathrm{C} 18$, $300 \AA, 250 \times 10 \mathrm{~mm}$ Phenomenex). Fractions with folded peptide were detected with MS as before, and their purity was assessed on an RP-HPLC (Shimadzu LC-10) with an analytical column (XSELECT CSH 130 C18 $2.5 \mu \mathrm{m}, 4.6 \times 150 \mathrm{~mm}$ column XP, Waters). Peptide purity was assessed to be $>95 \%$ by UV $(215 \mathrm{~nm})$. Fractions containing the folded peptide were lyophilized.

Antifouling Assay. Biofouling inhibition was tested with a similar experimental setup to that for barrettides A and B. ${ }^{19,24,49}$ In short, 20 $( \pm 2)$ cyprid larvae of the bay barnacle Amphibalanus improvisus were incubated in $9.9 \mathrm{~mL}$ of filtered seawater (FSW) $+100 \mu \mathrm{L}$ of additive, the additive being either $100 \mu \mathrm{L}$ of FSW, $100 \mu \mathrm{L}$ of sterile filtered $\mathrm{H}_{2} \mathrm{O}$ (controls), or $100 \mu \mathrm{L}$ of peptide dissolved in $\mathrm{MQ}-\mathrm{H}_{2} \mathrm{O}$ (treatment). Peptide concentrations tested were $0.06,0.6$, and $6 \mu \mathrm{M}$, all experiments were performed in triplicates, and the settling was assessed after 3 days of incubation. Statistical analyses were produced in $\mathrm{R}^{60}$ and included $\chi^{2}$ test, ggplot 2 for visualizations, ${ }^{61}$ and the package $\mathrm{drc}^{62}$ for dose-response curve and $\mathrm{IC}_{50}$ calculations.

Sample Description. Three G. barretti specimens (Gb01, Gb02, Gb03) were collected West of Yttre Vattenholmen (58.876233, 11.101483), Kosterfjord, Sweden, on May 4, 2016, at 84-96 m depth, using a remote operated vehicle on board the R/V Nereus. Samples were identified on board by PC, and subsamples for transcriptomics were flash-frozen on board in liquid $\mathrm{N}_{2}$ then kept at $-80{ }^{\circ} \mathrm{C}$ until RNA extraction; subsamples were also frozen for chemistry. A subsample of Gb01 was frozen and used to extract high molecular weight DNA for whole genome sequencing. Vouchers of Gb01, Gb02, and Gb03, stored in 96\% EtOH, have been deposited at the Zoological Museum of Uppsala (UPSZMC), Sweden, under museum numbers UPSZMC 184975, 184976, and 184977, respectively. Another four G. barretti transcriptomes were derived from specimens collected during the deep-sea expedition GS2017110 on the R/V G.O. Sars. Of those, one specimen came from Sula Reef, Norwegian Sea (64.0749, 8.0270, July 23, 2017, ROV dive 6, $267 \mathrm{~m}$ ) and three specimens came from Tromsøllaket, Barents Sea (71.5870, 21.3750, August 3, 2017, trawl 1, $333 \mathrm{~m}$ ); these four specimens were identified by Hans Tore Rapp, and vouchers are stored in the Riesgo lab at -80 ${ }^{\circ} \mathrm{C}$ under ROV6\#3Gb (Gb04), trawl1\#5Gb (Gb05), trawl1\#6Gb (Gb06), and trawl1\#8Gb (Gb07) (Natural History Museum, London, UK). Raw RNA sequencing data were obtained for these seven individuals of G. barretti (Gb01, Gb02, Gb03, Gb04, Gb05, Gb06, Gb07); for a complete description of the methods for the transcriptome sequencing, see Koutsouveli et al. ${ }^{51}$

Data Preparation. For G. barretti transcriptomes, raw data were quality checked with fastQC v.0.11.9. ${ }^{63}$ Transcriptomes were assembled with Trinity v.2.9.1/v.2.11. In parallel, the raw reads were also processed with trimmomatic v. $0.36^{64}$ and downsampled with khmer v.2.1.1 ${ }^{65}$ normalizing by median. The assemblies were cross-checked by Transrate v.1.0.166 with the trimmed and downsampled reads, and only the good transcripts were used for BLAST searches. The number of genes was approximated by counting the unique Trinity sequence cluster IDs. The metagenome ${ }^{29}$ is Roche 454 data and was also assembled with Trinity ${ }^{67}$ but without any further processing. Readily assembled sponge transcriptomes $(n=63)$ were provided by collaborators or downloaded from open data repositories (Supporting Information Table S1). 
BLAST Searches of Transcriptomes for Similar Sequences. For all sequencing data resources, local BLAST databases were built and searched (tblastn) with the amino acid sequences of barrettide $\mathrm{A}$ and $\mathrm{B}$ as queries. Tabular results were concatenated separately for $G$. barretti and all other sponges, asterisks and dashes were removed from the amino acid sequence of hits, and only those fitting the cysteine framework of barrettides were retained (Supporting Information Tables S2, S4).

Transcriptome Annotation. Transcriptome annotation was performed for one transcriptome (Gb01) following the Trinotate workflow. ${ }^{68}$ Open reading frames were extracted from the transcriptome with TransDecoder v. 5.5.0 (https://github.com/ TransDecoder/TransDecoder). The output was submitted to the online portal GhostKOALA v. 2.2 (https://www.kegg. $\mathrm{jp} /$ ghostkoala/), and open reading frames were annotated against KEGG database 'c family euk+genus prok. ${ }^{69}$

Manual Sequēnce Analysis. Barrettide hit sequences were manually extracted from the assemblies and barrettides present in ORFs were identified with https://web.expasy.org/translate/. The translated ORFs were submitted to SignalP-5.0 server ${ }^{31}$ (http://www. cbs.dtu.dk/services/SignalP/) for prediction of the signal peptide sequence. Translated barrettide ORFs were also submitted to a webtool (https://web.expasy.org/peptide_cutter/) for prediction of cleaving enzymes.

\section{ASSOCIATED CONTENT}

\section{(s) Supporting Information}

The Supporting Information is available free of charge at https://pubs.acs.org/doi/10.1021/acs.jnatprod.1c00938.

File S1: Information on Tables S1-S6 and Figures S1, S2 (PDF)

File S2: Tables S1-S6 (XLSX)

\section{AUTHOR INFORMATION}

\section{Corresponding Author}

Paco Cárdenas - Pharmacognosy, Department of

Pharmaceutical Biosciences, Biomedical Centre, Uppsala

University, 75123 Uppsala, Sweden; 이이.org/0000-

0003-4045-6718; Phone: +46 (0)18 471 4934;

Email: paco.cardenas@farmbio.uu.se

\section{Authors}

Karin Steffen - Pharmacognosy, Department of Pharmaceutical Biosciences, Biomedical Centre, Uppsala University, 75123 Uppsala, Sweden; (1) orcid.org/00000003-0499-1430

Quentin Laborde - Pharmacognosy, Department of Pharmaceutical Biosciences, Biomedical Centre, Uppsala University, 75123 Uppsala, Sweden

Sunithi Gunasekera - Pharmacognosy, Department of Pharmaceutical Biosciences, Biomedical Centre, Uppsala University, 75123 Uppsala, Sweden; O orcid.org/00000002-1089-4015

Colton D. Payne - School of Biomedical Sciences, The University of Queensland, Brisbane, QLD 4072, Australia

K. Johan Rosengren - School of Biomedical Sciences, The University of Queensland, Brisbane, QLD 4072, Australia; (1) orcid.org/0000-0002-5007-8434

Ana Riesgo - Department of Life Sciences, The Natural History Museum, London SW7 5BD, United Kingdom; Department of Biodiversity and Evolutionary Biology, Museo Nacional de Ciencias Naturales-CSIC, 28006 Madrid, Spain

Ulf Göransson - Pharmacognosy, Department of Pharmaceutical Biosciences, Biomedical Centre, Uppsala
University, 75123 Uppsala, Sweden; 다이.org/00000002-5005-9612

Complete contact information is available at:

https://pubs.acs.org/10.1021/acs.jnatprod.1c00938

\section{Notes}

The authors declare no competing financial interest.

\section{ACKNOWLEDGMENTS}

The authors thank V. Koutsouveli and the Riesgo lab for providing assembled transcriptomes of many sponges included in this study, as well as the raw data for G. barretti. The authors thank F. Lundmark for teaching and improving SPPS methods and chemistry, and C. Chi for NMR experimental advice, troubleshooting, and providing a suitable $\mathrm{pH}$-meter. This study made use of the NMR Uppsala infrastructure, which is funded by the Department of Chemistry - BMC and the Disciplinary Domain of Medicine and Pharmacy. The authors thank I. Erngren for helping analyze metabolomic data and $\mathrm{M}$. Ogemark for providing cyprid larvae for the bioassays. The computations were performed on resources provided by the Swedish National Infrastructure for Computing (SNIC) at Uppmax. K.S. and P.C. thank the SciLifeLab/NBIS WABI long-term support for expertise and work provided for the whole genome sequencing. The authors thank all the people involved in the sampling of all the specimens underlying this work. K.S. thanks the Swedish pharmaceutical society (Apotekarsocieteten) for funds provided to purchase reagents for SPPS. K.S., A.R., and P.C. acknowledge SponGES; SponGES has received funding from the European Union's Horizon 2020 research and innovation program under grant agreement no. 679849. This document reflects only the authors' view, and the Executive Agency for Small and Medium-sized Enterprises (EASME) is not responsible for any use that may be made of the information it contains. The authors thank the Editor-in-Chief and the two anonymous reviewers for their valuable input.

\section{REFERENCES}

(1) Leal, M. C.; Puga, J.; Serôdio, J.; Gomes, N. C. M.; Calado, R. PLoS One 2012, 7, No. e30580.

(2) Kornprobst, J.-M. Porifera (Sponges). Encyclopedia of Marine Natural Products, 2nd ed.; Wiley-VCH: Weinheim, 2014; Vol. 2, pp 607-1086, OCLC: 931543490

(3) Galitz, A.; Nakao, Y.; Schupp, P. J.; Wörheide, G.; Erpenbeck, D. Mar. Drugs 2021, 19, 448.

(4) Unson, M. D.; Holland, N. D.; Faulkner, D. J. Mar. Biol. 1994, $119,1-11$.

(5) Wilson, M. C.; et al. Nature 2014, 506, 58-62.

(6) Slaby, B. M.; Hackl, T.; Horn, H.; Bayer, K.; Hentschel, U. ISME J. 2017, 11, ismej2017101.

(7) Tianero, M. D.; Balaich, J. N.; Donia, M. S. Nature Microbiology 2019, 4, 1149-1159.

(8) El Maddah, F.; Eguereva, E.; Kehraus, S.; König, G. M. Org. Biomol. Chem. 2019, 17, 2747-2752.

(9) Mohanty, I.; Podell, S.; Biggs, J. S.; Garg, N.; Allen, E. E.; Agarwal, V. Mar. Drugs 2020, 18, 124.

(10) Podell, S.; Blanton, J. M.; Oliver, A.; Schorn, M. A.; Agarwal, V.; Biggs, J. S.; Moore, B. S.; Allen, E. E. Microbiome 2020, 8, 97.

(11) Rust, M.; Helfrich, E. J. N.; Freeman, M. F.; Nanudorn, P.; Field, C. M.; Rückert, C.; Kündig, T.; Page, M. J.; Webb, V. L.; Kalinowski, J.; Sunagawa, S.; Piel, J. Proc. Natl. Acad. Sci. U. S. A. 2020, 117, 9508-9518. 
(12) Storey, M. A.; Andreassend, S. K.; Bracegirdle, J.; Brown, A.; Keyzers, R. A.; Ackerley, D. F.; Northcote, P. T.; Owen, J. G. mBio 2020, 11, e02997-19.

(13) Bowerbank, J. Philos. Trans. R. Soc. London 1858, 148, 279332.

(14) Bohlin, L.; Cárdenas, P.; Backlund, A.; Göransson, U. In Blue Biotechnology; Müller, W. E. G., Schröder, H. C., Wang, X., Eds.; Springer International Publishing: Cham, 2017; Vol. 55; pp 1-34.

(15) Ackermann, D.; List, P. H. Hoppe-Seyler's Z. Physiol. Chem. 1957, 308, 270-273.

(16) Ackermann, D.; List, P. H. Hoppe-Seyler's Z. Physiol. Chem. 1958, 309, 286-290.

(17) Erngren, I.; Smit, E.; Pettersson, C.; Cárdenas, P.; Hedeland, M. Front. Chem. 2021, 9, 662659.

(18) Lidgren, G.; Bohlin, L.; Bergman, J. Tetrahedron Lett. 1986, 27, 3283-3284.

(19) Sjögren, M.; Goransson, U.; Johnson, A. L.; Dahlstrom, M.; Andersson, R.; Bergman, J.; Jonsson, P. R.; Bohlin, L. J. Nat. Prod. 2004, 67, 368-372.

(20) Sölter, S. Identifizierung und Synthese von Naturstoffen aus borealen Schwämmen. Ph.D. thesis, Universität Hamburg, Hamburg, 2004.

(21) Hedner, E.; Sjögren, M.; Frändberg, P.-A.; Johansson, T.; Göransson, U.; Dahlström, M.; Jonsson, P.; Nyberg, F.; Bohlin, L. J. Nat. Prod. 2006, 69, 1421-1424.

(22) Olsen, E. K.; Hansen, E.; Moodie, L.; Isaksson, J.; Sepcic, K.; Cergolj, M.; Svenson, J.; Andersen, J. H. Org. Biomol. Chem. 2016, 14, 1629-1640.

(23) Di, X.; Rouger, C.; Hardardottir, I.; Freysdottir, J.; Molinski, T.; Tasdemir, D.; Omarsdottir, S. Mar. Drugs 2018, 16, 437.

(24) Carstens, B. B.; Rosengren, K. J.; Gunasekera, S.; Schempp, S.; Bohlin, L.; Dahlström, M.; Clark, R. J.; Göransson, U. J. Nat. Prod. 2015, 78, 1886-1893.

(25) Darwin, C. A Monograph on the Sub-Class Cirripedia with Figures of All the Species. The Balanidae, (or Sessile Cirripedia); the Verricidae, etc., etc., etc.; The Ray Society: London, 1854; p 250.

(26) Fortunato, S.; Adamski, M.; Bergum, B.; Guder, C.; Jordal, S.; Leininger, S.; Zwafink, C.; Rapp, H.; Adamska, M. EvoDevo 2012, 3, 14.

(27) Srivastava, M.; et al. Nature 2010, 466, 720-726.

(28) Kenny, N. J.; et al. Nat. Commun. 2020, 11, 3676.

(29) Radax, R.; Rattei, T.; Lanzen, A.; Bayer, C.; Rapp, H. T.; Urich, T.; Schleper, C. Environ. Microbiol. 2012, 14, 1308-1324.

(30) Arnison, P. G.; et al. Nat. Prod. Rep. 2013, 30, 108-160.

(31) Almagro Armenteros, J. J.; Tsirigos, K. D.; Sønderby, C. K.; Petersen, T. N.; Winther, O.; Brunak, S.; von Heijne, G.; Nielsen, H. Nat. Biotechnol. 2019, 37, 420-423.

(32) Mayr, C. Cold Spring Harbor Perspect. Biol. 2019, 11, a034728.

(33) Sarkar, N. Annu. Rev. Biochem. 1997, 66, 173-197.

(34) Toro, N.; Molina-Sánchez, M. D.; Nisa-Martínez, R.; MartínezAbarca, F.; García-Rodríguez, F. M. In Transposons and Retrotransposons; Garcia-Pérez, J. L., Ed.; Springer New York: New York, NY, 2016; Vol. 1400; pp 21-32.

(35) Hausner, G.; Hafez, M.; Edgell, D. R. Mobile DNA 2014, 5, 8.

(36) Willey, J. M. Prescott's Microbiology, 11th ed.; McGraw-Hill Education: New York, NY, 2020.

(37) Carroll, A. R.; Copp, B. R.; Davis, R. A.; Keyzers, R. A.; Prinsep, M. R. Nat. Prod. Rep. 2020, 37, 175-223.

(38) Kossel, A. Archiv. Physiologie 1891, 181-186.

(39) Gold, D. A.; Grabenstatter, J.; de Mendoza, A.; Riesgo, A.; Ruiz-Trillo, I.; Summons, R. E. Proc. Natl. Acad. Sci. U. S. A. 2016, 113, 2684-2689.

(40) Zumberge, J. A.; Love, G. D.; Cárdenas, P.; Sperling, E. A.; Gunasekera, S.; Rohrssen, M.; Grosjean, E.; Grotzinger, J. P.; Summons, R. E. Nature Ecology \& Evolution 2018, 2, 1709-1714.

(41) Love, G. D.; Zumberge, J. A.; Cárdenas, P.; Sperling, E. A.; Rohrssen, M.; Grosjean, E.; Grotzinger, J. P.; Summons, R. E. Nature Ecology \& Evolution 2020, 4, 34-36.
(42) Turon, X.; Becerro, M. A.; Uriz, M. J. Cell Tissue Res. 2000, 301, $311-322$.

(43) Roué, M.; Domart-Coulon, I.; Ereskovsky, A.; Djediat, C.; Perez, T.; Bourguet-Kondracki, M.-L. J. Nat. Prod. 2010, 73, 12771282.

(44) Thompson, J. E.; Barrow, K. D.; Faulkner, D. Acta Zool. 1983, 64, 199-210.

(45) Ternon, E.; Zarate, L.; Chenesseau, S.; Croué, J.; Dumollard, R.; Suzuki, M. T.; Thomas, O. P. Sci. Rep. 2016, 6, 29-474.

(46) Simmons, T. L.; Coates, R. C.; Clark, B. R.; Engene, N.; Gonzalez, D.; Esquenazi, E.; Dorrestein, P. C.; Gerwick, W. H. Proc. Natl. Acad. Sci. U. S. A. 2008, 105, 4587-4594.

(47) Flatt, P. M.; Gautschi, J. T.; Thacker, R. W.; Musafija-Girt, M.; Crews, P.; Gerwick, W. H. Mar. Biol. 2005, 147, 761-774.

(48) Schroeder, C. I.; Rosengren, K. J. In Snake and Spider Toxins; Priel, A., Ed.; Springer US: New York, NY, 2020; Vol. 2068; pp 129162.

(49) Sjögren, M.; Johnson, A.-L.; Hedner, E.; Dahlström, M.; Göransson, U.; Shirani, H.; Bergman, J.; Jonsson, P. R.; Bohlin, L. Peptides 2006, 27, 2058-2064.

(50) Willemsen, P. R.; Overbeke, K.; Suurmond, A. Biofouling 1998, 12, 133-147.

(51) Koutsouveli, V.; Cárdenas, P.; Santodomingo, N.; Marina, A.; Morato, E.; Rapp, H. T.; Riesgo, A. Mol. Biol. Evol. 2020, 37, 34853506.

(52) Cárdenas, P.; Xavier, J. R.; Reveillaud, J.; Schander, C.; Rapp, H. T. PLoS One 2011, 6, No. e18318.

(53) Morozov, G.; Sabirov, R.; Anisimova, N. Journal of Natural History 2021, 55, 571-596.

(54) Shen, Y.; Bax, A. J. Biomol. NMR 2013, 56, 227-241.

(55) Cierpicki, T.; Otlewski, J. J. Biomol. NMR 2001, 21, 249-261.

(56) Güntert, P. Protein NMR Techniques; Humana Press: NJ, 2004; Vol. 278; pp 353-378.

(57) Brünger, A. T. Nat. Protoc. 2007, 2, 2728-2733.

(58) Chen, V. B.; Arendall, W. B.; Headd, J. J.; Keedy, D. A.; Immormino, R. M.; Kapral, G. J.; Murray, L. W.; Richardson, J. S.; Richardson, D. C. Acta Crystallogr., Sect. D: Biol. Crystallogr. 2010, 66, $12-21$.

(59) Cárdenas, P. J. Chem. Ecol. 2016, 42, 339-347.

(60) Team, R. C. R: A Language and Environment for Statistical Computing; R Foundation for Statistical Computing: Vienna, Austria, 2016.

(61) Wickham, H. ggplot2: Elegant Graphics for Data Analysis; Springer-Verlag: New York, 2009.

(62) Ritz, C.; Baty, F.; Streibig, J. C.; Gerhard, D. PLoS One 2015, 10, No. e0146021.

(63) Andrews, S. FastQC: a quality control tool for high throughput sequence data. 2010; http://www.bioinformatics.babraham.ac.uk/ projects/fastqc.

(64) Bolger, A. M.; Lohse, M.; Usadel, B. Bioinformatics 2014, 30, 2114-2120.

(65) Crusoe, M. R.; et al. F1000Research 2015, 4, 900.

(66) Smith-Unna, R.; Boursnell, C.; Patro, R.; Hibberd, J. M.; Kelly, S. Genome Res. 2016, 26, 1134-1144.

(67) Ren, X.; Liu, T.; Dong, J.; Sun, L.; Yang, J.; Zhu, Y.; Jin, Q. PLoS One 2012, 7, No. e51188.

(68) Bryant, D. M.; et al. Cell Rep. 2017, 18, 762-776.

(69) Kanehisa, M.; Sato, Y.; Morishima, K. J. Mol. Biol. 2016, 428, $726-731$. 